\title{
Реконструкция на централната част на ушната мида
}

\author{
Г. Бояджиев ${ }^{1}$, Р. Бенчев ${ }^{1}$, Г. Коджабашев² \\ ${ }^{1}$ УНГ-клиника на Медицински институт на МВР - Сосрия \\ ГОтделение по кожни и венерически болести на Медицински институт на МВР - София
}

\begin{abstract}
A case of spinocellular carcinoma of anthelix of the pinna is presented. Wide excision is decided to restore the skin of the foot sculpture made by retroauricular area and a resection of skin flap on the second stage.
\end{abstract}

\section{Резюме}

Представен е случай със спиноцелуларен карцином на антхеликса на дясната ушна мида. Реши се широката ексцизия да се възстанови с кожна пластика на краче, взето от задушната област, като кожното ламбо да се резицира на втори етап.

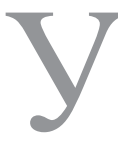

шната мида има кожно-хрущялен строеж и сложна форма. При туморни образувания или по-рядко при травматични увреди се налага да се запълни дефектът, който се получава. Това определено сруща трудности поради факта, че кожата е по-хлабаво свързана само по задната част, а по предната повьрхност пльтно следват сложните контури на хрущяла.

Според Weerda и Siegert дефектите на ушната мида се класифицират по следния начин:

Таблица 1. Класификация на аурикуларните дефекти според Weerda $и$ Siegert

\begin{tabular}{|l|l|l|}
\hline \multicolumn{3}{|c|}{ Класификация на аурикуларните дефекти } \\
\hline Централни & Периферни & Постаурикуларни \\
\hline ушен канал & хеликс & \\
\hline конха & горна част & субтотален \\
\hline антихеликс & средна част & \\
\hline комбиниран & долна част, лобулус & тотален \\
\hline
\end{tabular}

Повод за настоящата публикация стана изграждането на оперативен план за оперативното лечение на следния наш случай.
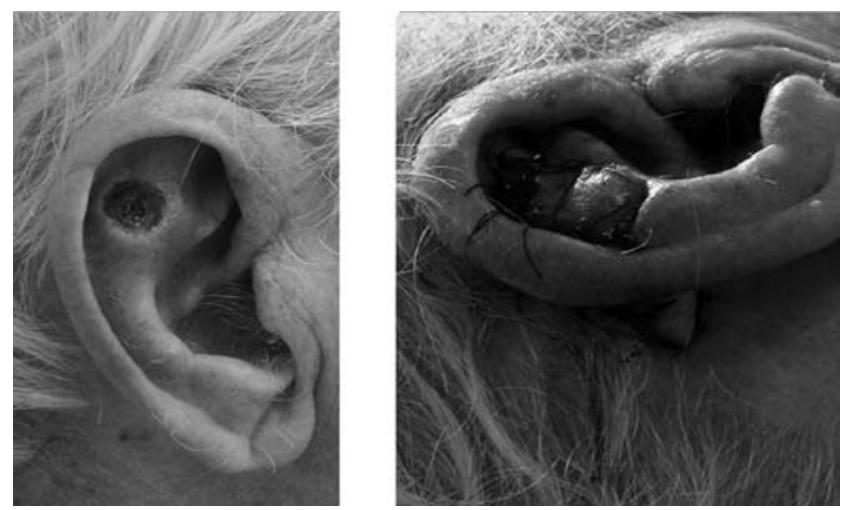

Фиг. 1. Спиноцелуларен карцином на ушната мида преди и след оперативното лечение. 
Вижда се, че туморьт дълбоко инфилтрира ушния хрущял и след резекцията му ще се оформи голям дефект. Когато по време на операцията се установи, че инфилтрацията не напредва към кожата по задната повърхност на ушната мида, се взе решение тя да се запази. Оформи се голямо кожно ламбо с цялостна кожа, а след мобилизиране на краищата на раната на ложето се заши с придръпване с П-образни шевове. Оформеното ламбо се „промуши“ през прорез на запазената кожа от долната страна, разстла се над дефекта и се заши. Конците се свалиха на 10-тия ден.

Ламбото се преряза на 3-тата седмица след сигурни данни, че се е захванало.
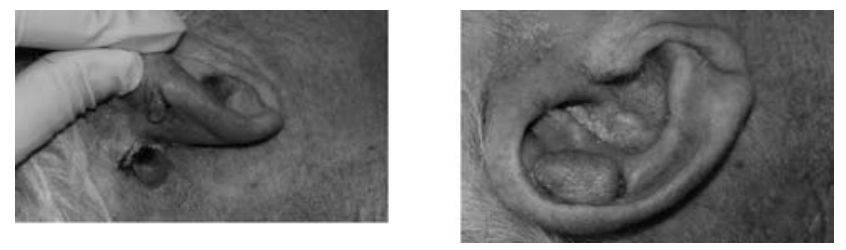

Фиг. 2. Прерязване на крачето на хранещото ламбо. Краен резултат.

Разглеждайки литературните източници за това как са разрешили проблема други отоларинголози, намерихме няколко оперативни методики.

На описаната по-долу схема се вижда, че в ретроаурикуларната област се очертава ламбо, базирано краниално, което се промушва през създадения дефект от резекцията на тумора. Основата на ламбото се резицира след 2-3 седмици.
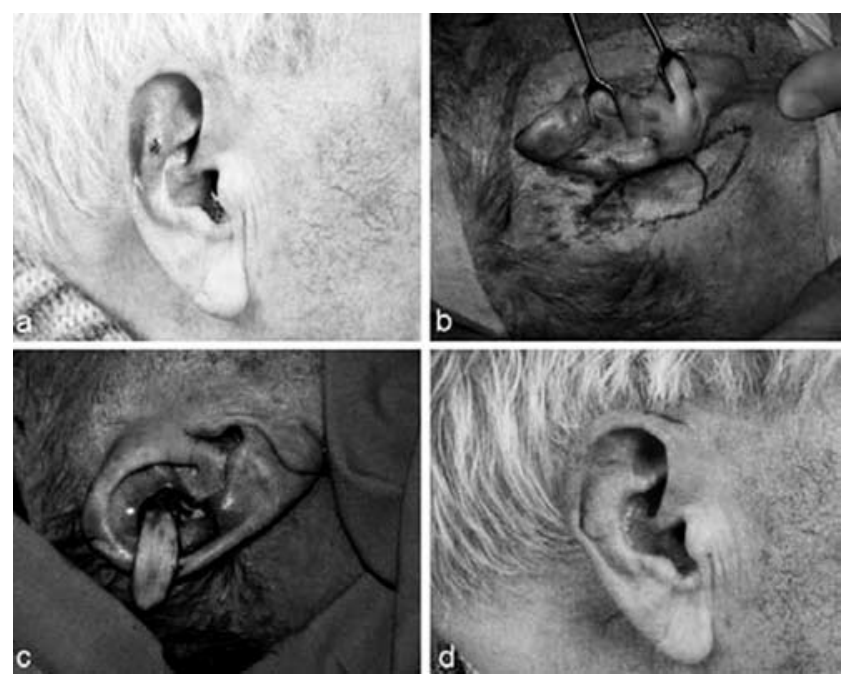

Фиг. 3. Реконструкция на централен дефект с краниално базирано островно ламбо. а) тумор; b) маркиране на ламбото; с) транспортиране на ламбото; d) резултат след няколко месеца.
Друга представена методика е е възстановяване на централен дефект с ламбо от задушната област по Lore (2005).
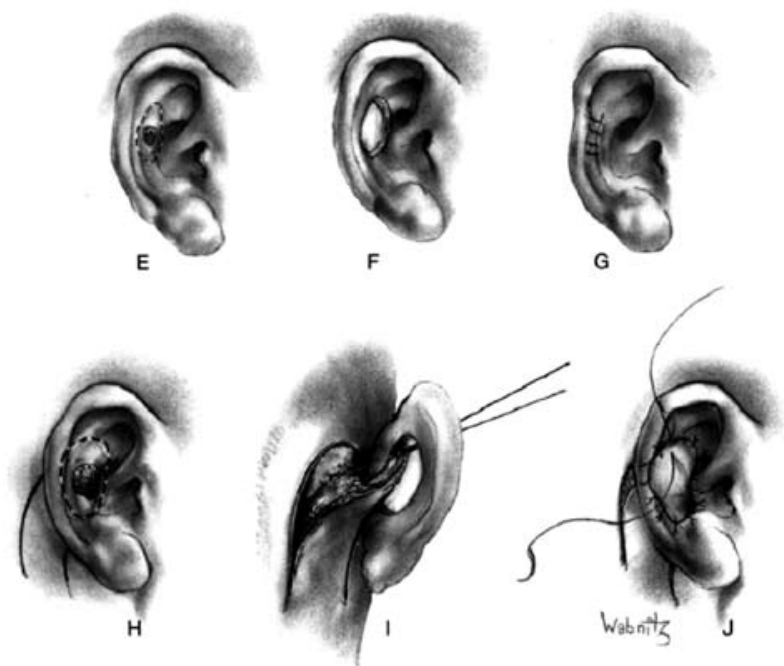

Фиг. 4. Възстановяване на централен дефект а modo Lore

Mark L. Gustafson, Myles L. Pensak, (2003) представят следната методика, която описва изтеглянето на кожно ламбо, изтеглено през кожен тунел, направен на задната част на ушната мида.

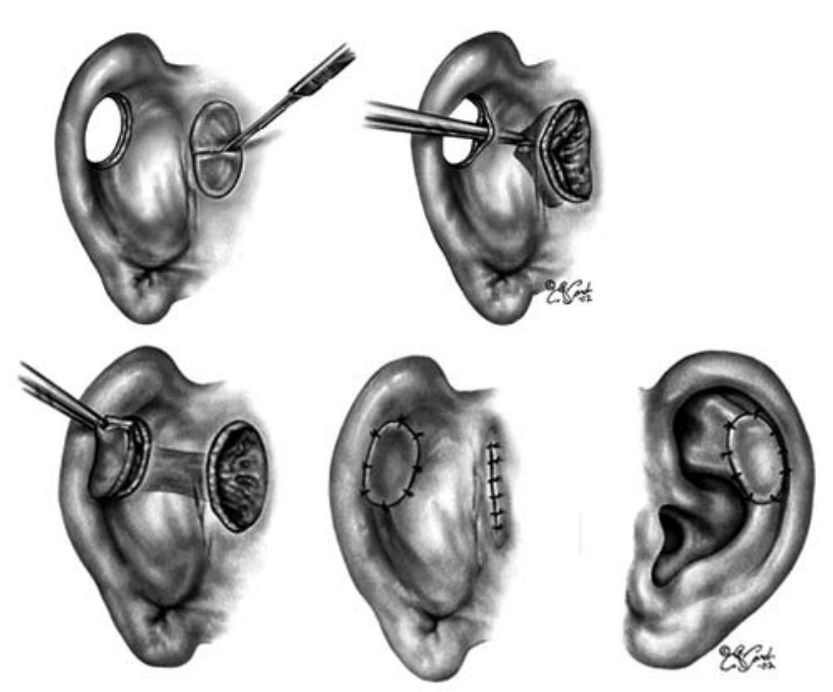

Фиг. 5. Възстановяване малък централен дефект чрез пренасяне на кожно ламбо през тунел, направен през задната повърхност на ушната мида.

Друг метод е представен от Weerda (1987), който оформя голямо двустранно ламбо от задушната област. 

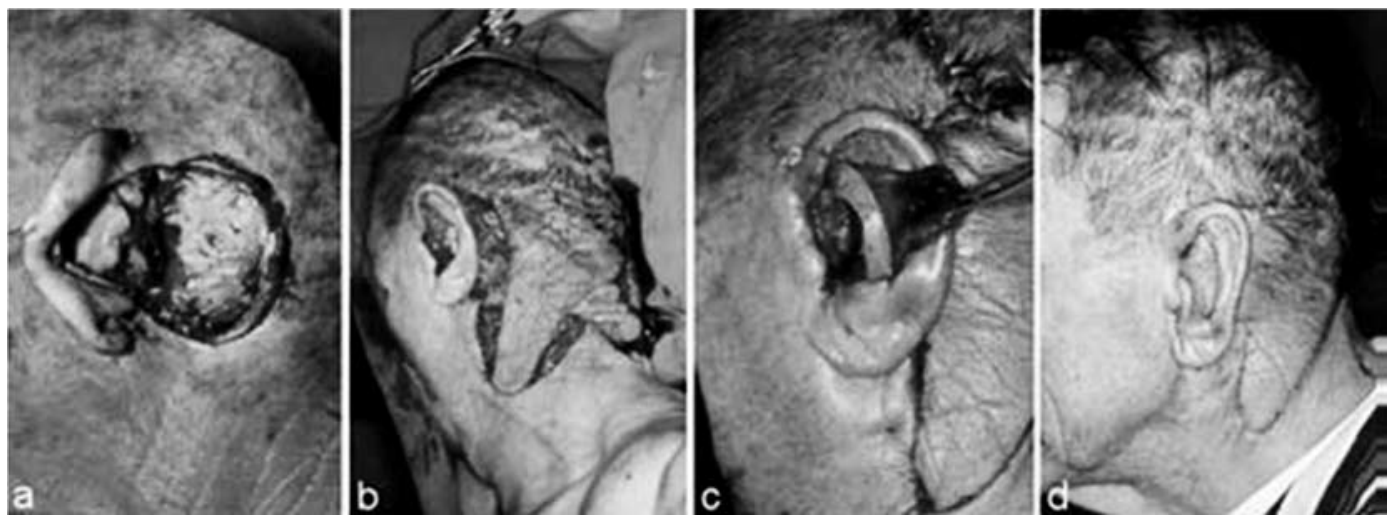

Фиг. 6. Метод на Weerda за възстановяване на дефект на централната част на ушната мида с билобно ламбо от задушната област.

\section{Заключение}

Описаният от нас способ е лесен и бърз метод за възстановяване целостта на задушната мида. Запазването на кожата от задната повърхност на ушната мида, която почти никога не се засяга от туморния процес, спомага за възстановяването и захранването на ламбото и определено подобрява козметичния резултат.

Другото предимство на описания от нас метод е доброто захранване на кожното ламбо при оформянето на основата му каудално, към върха на мастоида.

\section{Литература:}

1. Weerda H, Siegert R. Classification and treatment of aquireddeformities. Face. 1998; 6: 79-82

2. Weerda H. Plastic surgery of the ear. In: Kerr AG, editor. Scott Brown's diseases of the ear, nose and throat. 5th ed. London: Butterworth; 1987. p. 3.

3. Siegert R. The combined reconstruction of congenital auricular atresia and severe microtia. Laryngoscope. 2003; 113: 2021-9.

4. Siegert R. Correction of the Lobule. Facial Plastic Surgery. 2004; 20: 293-8.

5. Michael E. Glasscock, Aina Julianna Gulya. Surgery of the ear XV edition, 2003

6. Ballenger's Manual ofOtorhinolaryngology Head and Neck Surgery James B. Snow Jr, MD, 2002

7. John M. Lore, Jr., Jesus E. Medina. An Atlas of head and neck surgery, fourth edition, 2005

8. GMS Current Topics in Otorhinolaryngology - Head and Neck Surgery 2007, Vol. 6, ISSN 1865-1011

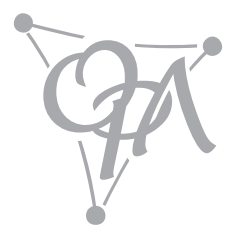

